\title{
Estabilidade fenotípica de alfaces em diferentes épocas e ambientes de cultivo ${ }^{1}$
}

\author{
Phenotypic stability of the lettuce in different periods and cropping environments
}

\author{
João Pedro da Silva Queiroz ${ }^{2}$, Andrey Jefferson Meneses da Costa ${ }^{2}$, Leonarda Grillo Neves ${ }^{3 *}$, Santino Seabra \\ Junior $^{3}$ e Marco Antônio Aparecido Barelli ${ }^{3}$
}

\begin{abstract}
RESUMO - Este trabalho teve como objetivo estimar a adaptabilidade e estabilidade fenotípica das cultivares de alface tipo crespa em diferentes épocas de cultivo em condições de alta temperatura. O delineamento experimental utilizado foi de blocos ao acaso em esquema fatorial 5 × 7 × 2, sendo cinco cultivares (Verônica, Vera, Cinderela, Isabela e Veneranda), sete ambientes (campo aberto, sombrite 30; 40;50\% de luz e malhas termo refletoras 30; 40 e $50 \%$ ) e duas épocas de cultivo (outubro a dezembro de 2008) e (julho a setembro de 2009), com quatro repetições. Em relação à produção total e produção comercial a cultivar Verônica foi a que se destacou com relação à produção. Houve diferença no desempenho produtivo das cultivares em relação às épocas de cultivo. E os parâmetros do coeficiente de determinação e índice de variação da variável número de folhas são próximos da unidade, apresentando uma maior estabilidade. A cultivar Verônica se manteve mais estável nos períodos de produção respondendo melhor às épocas de plantio independente dos ambientes de cultivos. A cultivar Cinderela, em relação às outras cultivares, manteve uma boa produção, sendo a segunda opção para o cultivo.
\end{abstract}

Palavras-chave: Lactuva sativa. Cultivos agrícolas-rendimento. Interação genótipo x ambiente.

\begin{abstract}
The objective of this study was to estimate the adaptability and phenotypic stability of cultivars of crisp lettuce in different growing seasons and under high-temperature conditions. The experimental design used was of randomized blocks in a $5 \times 7 \times 2$ factorial scheme, consisting of five cultivars (Veronica, Vera, Cinderella, Isabela and Veneranda), seven environments (open field, 30, 40 and 50\% shading, and 30, 40 and 50\% heat-reflective mesh), and two cropping seasons (October-December 2008 and July-September 2009) with four replications. In respect to both total and commercial production, the cultivar "Veronica" was that which most stood out. There were differences in yield performance of the cultivars in relation to the cropping seasons. The parameters, coefficient of determination and index of variation of the number of leaves, are close to one, showing greater stability. The cultivar "Veronica" remained more stable during periods of production, with a better response to the growing season, regardless of the environment. The cultivar "Cinderella", compared to the other cultivars, maintained good yield, being the second choice for farming.
\end{abstract}

Key words: Lactuva sativa. Crops yield. Interaction genotype and environment.

\footnotetext{
*Autor para correspondência

${ }^{1}$ Recebido para publicação em 13/09/2011; aprovado em 05/11/2013

Parte da Monografia de Graduação do primeiro autor apresentada na Universidade do Estado de Mato Grosso/UNEMAT, Cáceres-MT, Brasil

${ }^{2}$ Departamento de Agronomia, Universidade do Estado de Mato Grosso/UNEMAT, Cáceres-MT, Brasil, joaopedro_pocone@hotmail.com, andreyjeferson_agro@hotmail.com

${ }^{3}$ Departamento de Agronomia, Universidade do Estado de Mato Grosso/UNEMAT, Avenida São João, Cavalhada. Campus Universitário de Cáceres-MT, Cáceres-MT, Brasil, leonardaneves@unemat.br, mbarelli@unemat.br, santinoseabra@hotmail.com
} 


\section{INTRODUÇÃO}

Os estudos sobre a interação genótipo $\mathrm{x}$ ambiente vêm sendo importantes no desenvolvimento de novas cultivares. Diversos métodos visando estudar a interação genótipos $\mathrm{x}$ ambientes têm sido propostos, destacando-se aqueles que se baseiam nas análises de variância, na regressão linear, regressão não linear e na regressão segmentada (ROSSE; VENCOVSKY, 2000). A manifestação do potencial produtivo de uma espécie vegetal, dentre elas a alface, depende da interação genótipo $\mathrm{x}$ ambiente, onde a escolha da cultivar é decisiva para o sucesso do sistema de cultivo adotado (ECHER et al., 2001).

A avaliação de genótipos em diferentes ambientes permite estimar parâmetros genéticos - estatísticos que visam quantificar a interação genético - ambiente presente na expressão fenotípica de uma população. Tais estimativas são úteis para aumentar a eficiência da seleção (ROSSMANN, 2001). O estudo de parâmetros que estimam a adaptabilidade e estabilidade fenotípica serve desta forma, para caracterizar um grupo de genótipos quanto à sua resposta relativa às variações de ambiente.

O desafio para esta espécie é desenvolver genótipos tropicalizados, por ser uma espécie originalmente de clima ameno, porém apresenta alta demanda em todas as regiões do Brasil. A região de Cáceres-MT apresenta temperaturas elevadas praticamente durante o ano todo, onde a temperatura média é de $26,24{ }^{\circ} \mathrm{C}$ e as máximas podem alcançar $41^{\circ} \mathrm{C}$ (NEVES et al., 2011), este fato assume um papel de relevância na produção da alface, sendo importante o conhecimento do comportamento de genótipos com resistência a calor e que apresente alta produção com qualidade. Outra opção que pode mitigar os fatores climáticos é o cultivo protegido tipo telado, utilizando tela de sombreamento e termorrefletora, pois minimizam os efeitos da temperatura e da luminosidade excessivas. Porém, o tipo de tela e o percentual de sombreamento empregado dependerão das condições climáticas do período de cultivo e da cultivar utilizada (SEABRA JUNIOR, et al., 2012).

A utilização de cultivares adaptadas às condições ambientais de cada região aliada a práticas que visem à diminuição dos efeitos da luminosidade e temperatura pode contribuir para o aumento da qualidade e produtividade da alface (SILVA; LEAL; MALUF, 1999).

Este trabalho tem como objetivo estimar a adaptabilidade e estabilidade fenotípica de cultivares de alface tipo crespa em diferentes épocas de cultivo e ambientes em condições tropicais em Cáceres, Mato Grosso.

\section{MATERIAL E MÉTODOS}

Os experimentos foram conduzidos na área experimental de Horticultura da Universidade do Estado de Mato Grosso - UNEMAT, localizada no Município de Cáceres-MT. A região apresenta altitude média de $118 \mathrm{~m}$ do nível do mar, latitude de $16^{\circ} 04^{\prime} 33^{\prime}$ S e longitude 57 $39^{\prime} 10^{\prime \prime}$ W. Segundo a classificação de Köppen a região apresenta clima tropical quente semiúmido ( $\mathrm{Aw}$ ), com temperatura média do mês mais frio a $18,0{ }^{\circ} \mathrm{C}$. Apresenta inverno seco e chuvas no verão, com temperatura máxima anual de 31,5 e mínima média de $20,1{ }^{\circ} \mathrm{C}$, podendo ocorrer temperaturas de até $41^{\circ} \mathrm{C}$ (NEVES, 2011). O solo da área é do tipo Plintossolo.

O delineamento experimental utilizado foi de blocos ao acaso em esquema fatorial $5 \times 7 \times 2$, sendo cinco cultivares (Verônica, Vera, Cinderela, Isabela e Veneranda), sete ambientes (campo aberto, sombrite 30; 40 e 50 por cento de infiltração de luz e malhas termo refletoras $30 ; 40 ; 50$ por cento de infiltração de luz) e duas épocas de cultivo de verão (outubro a dezembro de 2008) e cultivo de inverno (julho a setembro de 2009), com quatro repetições, onde cada parcela foi composta de dezesseis plantas, avaliando as seis plantas centrais, descartando as demais como bordadura.

As cultivares utilizadas neste estudo foram recomendadas pelas empresas produtoras de semente, como materiais potencias para estudos em condições de alta temperatura e apresentavam as seguintes características: tipo solta crespa, com porte grande, coloração variando de verde claro a brilhante, alta resistência ao pendoamento precoce e ciclo variando de 60 a 70 dias.

As mudas de alface foram produzidas em bandejas de polietileno expandido do tipo 128/6, preenchidas com substrato comercial. Estas foram irrigadas duas vezes ao dia com regadores manuais. $\mathrm{O}$ transplante foi realizado aos 30 dias após semeadura, quando as plantas apresentaram quatro folhas definitivas e usando o espaçamento de $0,3 \times 0,3 \mathrm{~m}$.

A área de cada ambiente possui a dimensão média de $(10 \times 10 \mathrm{~m})$ e continha cinco canteiros com $9 \mathrm{~m}$ de comprimento e $1,5 \mathrm{~m}$ de largura. Os telados apresentavam o pé direito de $2,40 \mathrm{~m}$ de altura, estes foram cobertos com diferentes tipos de tela de sombreamento e termo-refletora.

A adubação de plantio foi realizada de acordo com análise química do solo baseando nas recomendações de Trani et al. (1997) e Filgueira (2003). A adubação de cobertura foi realizada aos 7 e 14 dias após o transplante utilizando torta de mamona $(4,5 \% \mathrm{~N})$, totalizando $90 \mathrm{~kg} \mathrm{ha}^{-1}$ de nitrogênio. 
A irrigação foi do tipo micro-aspersão com mangueiras microfuradas do tipo Santeno I, disposta entre os canteiros. A irrigação foi monitorada com tensiômetro de solo instalado a $0,2 \mathrm{~m}$ de profundidade. Para o controle de plantas daninhas foi utilizado palha de milheto (Pennisetum americanum L.) sobre os canteiros e capinas manuais.

Aos 30 dias após o transplante realizou-se a colheita das seis plantas centrais onde foram levadas para o laboratório e submetidas à análise das características de: produção total - (PT), obtido pela média da parte aérea, peso fresco, da planta sem a retirada das folhas velhas; produção comercial - (PC), obtida pela média da parte aérea da planta, peso fresco, após a realização da limpeza das folhas velhas e caule sobressalente; e número de folhas - (NF), considerando as folhas que possuíam mais de $1,5 \mathrm{~cm}$ e sem se apresentar danificadas ou estar em senescência.

Os dados coletados foram submetidos à análise de variância. Considerando o efeito do genótipo como fixo e ambiente aleatório, sendo a natureza do modelo misto. A avaliação conjunta das épocas verão e inverno foram analisados através da análise de variância realizada com as médias das parcelas baseada no seguinte modelo matemático (CRUZ, 2005) (Equação 1):

$Y i j k=m+G i+A j+G A i j+(B / L) A j k m+G L i k+$

$A L j k+G A L i j k+E i j k$

em que: $m$ : média geral; $G i$ : efeito do i-ésimo genótipo (cultivar) (i = 1, 2, 3, 4, 5); Aj: efeito do j-ésimo ambiente de cultivo (A) $(\mathrm{j}=1,2,3,4,5,6,7)$; GAij: efeito da interação do i-ésimo genótipo com o jésimo ambiente; (B/L) Ajkm: efeito do k-ésimo bloco dentro do j-ésimo ambiente $(\mathrm{k}=1,2,3,4)$; GLik: efeito da interação do iésimo genótipo com o k-local (época $=1,2$ ); $A L j k$ : efeito da interação do j-ésimo ambiente com o k-local (época); GALijk: efeito da interação do i-ésimo genótipo, j-ésimo ambiente com o k-local (época); Eijk: erro aleatório.

Na comparação entre médias foi utilizado o teste Tukey a 5\% e com base nas estimativas de variância foram estimados os seguintes parâmetros genéticos: componente de variância genotípica, do componente de variância da interação genótipo $\mathrm{x}$ ambiente, da herdabilidade ou determinação genotípica, do coeficiente de variação genético e da razão entre os coeficientes de variação genéticos e ambientais visando avaliar a variação total de cada genótipo explicado pelo modelo empregado.

A metodologia utilizada para estimar a análise de adaptabilidade e estabilidade foi pelo Método Tradicional que consiste na análise conjunta dos experimentos, onde os efeitos causados pelos ambientes na interação genótipo $\mathrm{x}$ ambiente em cada genótipo são usados para estimar a estabilidade do genótipo demonstrando assim qual o mais estável às variações. Este método foi escolhido por ter a vantagem de poder ser aplicado com um número reduzido de ambientes (CRUZ, 2005).

O estimador do parâmetro de estabilidade foi descrito pela equação 2 :

$\mathrm{QM}(\mathrm{A} / \mathrm{Gi})=[\mathrm{r} /(\mathrm{a}-1)] \cdot\left[\sum \mathrm{Y}_{\mathrm{IJ}}^{2}-\left(\mathrm{Y}_{\mathrm{i}}\right)^{2} / \mathrm{a}\right]$

onde "a" é o grau de liberdade (GL) relacionado a fonte de variação do quadrado médio (QM), A : ambiente, G : genótipo, $\mathrm{r}$ : repetição, $\mathrm{Y}$ : parcela.

Esses parâmetros foram estimados a partir do programa computacional Genes-versão Windows, 2009 (CRUZ, 2006).

\section{RESULTADOS E DISCUSSÃO}

As fontes de variações avaliadas na (Tabela 1) apresentaram-se significativos para as cultivares (G), épocas (E), sendo que a fonte de variação do ambiente (A) demonstrou ser não significativo sobre as variáveis estudadas. A interação entre G x E e E x A apresentaram-se significativos com exceção das interações entre $G \times A$ e G x E x A que não apresentaram significância. Desta maneira, as fontes de variação que apresentaram diferença significativa para as variáveis, produção total, produção comercial e número de folhas avaliadas nos mostra que existe pelo menos um genótipo com desempenho diferenciado entre as cultivares avaliadas, e existe diferença significativa entre as épocas de cultivo.

Os resultados da análise de variância (Tabela 1) apresentaram médias das características de produção total (PT) 197,83 g planta $^{-1}$, produção comercial (PC) 174,99 g planta $^{-1}$ e número de folhas - (NF) 17,15 folhas/ planta. Este resultado de produção total foi inferior ao encontrado por Salatiel et al. (2001) que verificaram valores de produção total variando de 249,4 a 257,8 g planta $^{-1}$ para as cultivares Verônica e Vera em estudo realizado na cidade de Jaboticabal-SP. Rodrigues et al. (2008) constataram valores de produção total variando de 26,96 a 104,61 g planta $^{-1}$ e comercial de 25,54 a 96,7 g planta $^{-1}$ ao avaliarem diferentes cultivares no período de novembro a dezembro em Iranduba-AM, estes resultados apresentaram médias inferiores aos encontrados neste trabalho, se tratando da média das duas épocas de plantio.

Para números de folhas Queiroga et al. (2001) analisaram o cultivo de alface sob diferentes telas de sombreamento e observaram média de número de folhas de 20,75 a 22,30 por planta entre as cultivares Great Lakes, Verônica e Regina, sendo resultados superiores aos encontrados neste trabalho tendo média de 17,15. E 
resultados superiores também foram encontrados por Bezerra Neto et al. (2005) que verificaram médias de número de folhas entre os ambientes de ampla luminosidade de 16,05 a 18,28. Sugere-se que esta diferença de resultados encontrados pode estar relacionada à diferença entre os ambientes de cultivo, pois a característica número de folhas pode ser influenciada pelo ambiente, clima e pelo fator genético do material. Radin et al. (2004) constataram que ao avaliar o número de folhas de alface cultivadas em campo aberto e ambiente protegido, que quando a cultura é conduzida em ambiente protegido apresenta número de folhas maior do que as cultivadas em campo aberto. Isso ressalta que a utilização de ambiente protegido ajuda no aumento de número de folhas, ou seja, telados proporcionam maior número de folhas, do que quando cultivado sob radiação solar direta, principalmente em região de clima tropical. Resultado este não confirmado pelo presente estudo.
Dentre as características de produção da alface, podem-se destacar o número de folhas por planta e a massa fresca da planta inteira, que podem ser influenciados pela cultivar, fotoperíodo e temperatura (OLIVEIRA et al., 2003). Bezerra Neto et al. (2005) em trabalho com alface verificaram que o sombreamento proporcionou maior produção de massa seca, tanto na fase de formação de mudas quanto na fase de campo. O cultivo sob ambiente protegido com telas de sombreamento vem sendo cada vez mais utilizado, pois reduz a incidência direta dos raios solares nas espécies que necessitam menor fluxo de energia radiante (BEZERRA NETO et al., 2005). Há diversos tipos de telas que podem ser utilizados para sombreamento, como telas de sombreamento e termo refletoras e em diversas intensidades de sombra. Sendo que telas termo refletoras podem apresentar vantagem relacionada com a passagem de luz sem calor em forma de luz difusa,

Tabela 1 - Resumo da análise de variância das características produção total (PT), produção comercial (PC) e número de folhas $(\mathrm{NF})$, e Estimativa da variância genotípica $\left(\sigma_{\mathrm{G}}^{2}\right)$, genótipo x época $\left(\sigma_{\mathrm{GxF}}^{2}\right)$, genótipo x ambiente $\left(\sigma_{\mathrm{GxA}}^{2}\right)$, genótipo x época x ambiente $\left(\sigma_{\mathrm{GXExA}}^{2}\right)$, residual $\left(\sigma_{\mathrm{R}}^{2}\right)$, coeficiente de determinação $\left(\mathrm{H}^{2}\right)$, coeficiente de variação genético $\left(\mathrm{cv}_{\mathrm{g}}\right)$ e do índice de variação $\left(\mathrm{I}_{\mathrm{V}}\right)$ das cultivares de alface cultivado em duas épocas: verão de 2008 e inverno de 2009 UNEMAT, Cáceres, 2011

\begin{tabular}{|c|c|c|c|c|}
\hline \multirow{2}{*}{ F.V. } & \multirow{2}{*}{ G.L. } & \multicolumn{3}{|c|}{ Q.M. } \\
\hline & & PT & $\mathrm{PC}$ & NF \\
\hline$(\mathrm{Bloco} / \mathrm{A}) / \mathrm{E}$ & 42 & 11044,2701 & 9029,1684 & 18,3046 \\
\hline Cultivares (G) & 4 & $50401,9106 *$ & $40108,6929 *$ & $176,7195^{*}$ \\
\hline Épocas (E) & 1 & $1969351,4760 *$ & $1505596,8943^{*}$ & $2176,7588^{*}$ \\
\hline Ambientes (A) & 6 & $8456,5818^{\mathrm{NS}}$ & $8056,1483^{\mathrm{NS}}$ & $18,8179^{\mathrm{NS}}$ \\
\hline $\mathrm{G} \times \mathrm{E}$ & 4 & $17017,3567 *$ & $12462,4469 *$ & $6,8423 *$ \\
\hline$G \times A$ & 24 & $1076,7849^{\mathrm{NS}}$ & $906,8367^{\mathrm{NS}}$ & $3,2786^{\mathrm{NS}}$ \\
\hline $\mathrm{E} \times \mathrm{A}$ & 6 & $55684,4244 *$ & $41369,9909 *$ & $97,5693 *$ \\
\hline $\mathrm{G} \times \mathrm{E} \times \mathrm{A}$ & 24 & $1227,6314^{\mathrm{NS}}$ & $969,3781^{\mathrm{NS}}$ & $2,4365^{\mathrm{NS}}$ \\
\hline Resíduo & 168 & 1347,6551 & 1132,4283 & 3,3940 \\
\hline Média & & 197,8275 & 174,9853 & 17,1517 \\
\hline $\mathrm{CV}(\%)$ & & 18,55 & 19,23 & 10,74 \\
\hline \multicolumn{5}{|c|}{ Estimativa dos Parâmetros Genéticos } \\
\hline$\sigma^{2} \mathrm{G}$ & & 598,8464 & 494,7997 & 3,0184 \\
\hline$\sigma^{2} \mathrm{G} \times \mathrm{E}$ & & 451,1350 & 328,3733 & 0,1258 \\
\hline$\sigma^{2} \mathrm{G} \times \mathrm{A}$ & & $-15,0846$ & $-6,2541$ & 0,0842 \\
\hline$\sigma^{2} \mathrm{G} \times \mathrm{E} \times \mathrm{A}$ & & $-24,0047$ & $-32,6100$ & $-0,1915$ \\
\hline$\sigma_{\mathrm{R}}^{2}$ & & 1347,6551 & 1132,4283 & 3,3940 \\
\hline $\mathrm{H}^{2}$ & & 0,6654 & 0,6908 & 0,9565 \\
\hline $\mathrm{Cv}_{\mathrm{g}}$ & & 12,37 & 12,712 & 10,1294 \\
\hline$I_{v}$ & & 0,6666 & 0,661 & 0,943 \\
\hline
\end{tabular}

(*) Significativo a $5 \%$ e $\left({ }^{\mathrm{NS}}\right)$ não significativo, pelo teste F; PT - produção total, PC - produção comercial $\left(\mathrm{g}^{\text {p planta }}{ }^{-1}\right)$, NF - número de folhas 
diminuindo a temperatura por ser revestida de alumínio (SANTOS; SEABRA JUNIOR; NUNES, 2010).

A interação $G \times$ E apresentou-se significativo, mostrando que das cinco cultivares avaliadas nas duas épocas de cultivo, pelo menos uma das cultivares obtive em cada época um desempenho diferenciado das variáveis avaliadas. Para a interação entre E x A foi significativo, constatando desta maneira que com o uso dos ambientes nas duas épocas de cultivo, para todas as variáveis estudas, propiciou um desempenho diferenciado das cultivares (Tabela 1). No desenvolvimento do trabalho observouse que não houve tamanha interação das cultivares com os ambientes como os encontrados por Gualberto, Oliveira e Guimarães (2009), essa baixa interação pode estar relacionada às condições climáticas adversas da região de Cáceres $\mathrm{MT}$, altas temperaturas, baixa umidade relativa do ar (SANTOS; SEABRA JUNIOR; NUNES, 2010). No entanto, os diferentes ambientes não apresentaram influência a ponto de promover alterações no comportamento do genótipo, apresentando desta forma estabilidade da produção.

Em relação aos parâmetros genéticos o coeficiente de determinação do índice de variação $\left(I_{v}\right)$ apresentou valores elevados para o número de folhas com $94 \%$ sendo superiores ao obtido para as variáveis massa fresca total com $66 \%$ e massa fresca comercial com 66\%. Silva, Leal e Maluf (1999) encontraram resultados semelhantes para pendoamento precoce em populações de alface tolerantes ao calor. Por meio destes resultados, torna-se real a possibilidade de ganhos expressivos na seleção de cultivares eficientes nos ambientes em estudo, o que é corroborado pelas estimativas das razões entre os coeficientes de variação genética e experimental $\left(\mathrm{CV}_{\mathrm{G}} / \mathrm{CV}_{\mathrm{E}}\right)$, que expressaram valores próximos ou superiores à unidade. É importante avaliar as magnitudes das interações genótipo $\mathrm{x}$ ambiente, esse conhecimento orienta na recomendação de cultivares para uma dada região e período de cultivo. Diamante et al. (2013) estudaram a interação entre cultivares de alface lisa (Regina, Elizabeth, Elisa e Regiane) em diferentes ambientes (campo aberto, telas de sombreamento e termorefletora 30 e $50 \%$ de infiltração de luz) em Cáceres MT e verificaram a não interação entre os fatores estudados. E que as condições ambientais não proporcionaram diferenças significativas nas condições de inverno.

Contudo, o processo tradicional de investigar as interações é a análise conjunta da variância e de grupos de experimentos. Os parâmetros estimados são úteis, e fornecem uma indicação adequada da resposta dos cultivares aos diferentes ambientes. Portanto, conclui-se que análises complementares são necessárias, principalmente devido ao modelo aqui estudado ser do tipo misto. As estimativas do coeficiente de determinação $\left(\mathrm{H}^{2}\right)$ apresentados variaram dentre as características avaliadas, apresentando para massa fresca total $66 \%$, massa fresca comercial $69 \%$ sendo inferiores à variável número de folhas com 95\%, atestando que as variações do ambiente trariam contribuição inferior às variações totais, indicando que as diferenças entre as características são atribuídas, principalmente, a causas genéticas. Estudo realizado por Souza et al. (2008) sobre variabilidade genética para características agronômicas em progênies de alface tolerantes ao calor realizado em Vitoria de Santo Antão - PE encontraram valores de coeficiente de herdabilidade no sentido restrito com 83,99; 78,79 e 80,82\% para as características de número de folhas, massa fresca e diâmetro da planta respectivamente, resultado encontrado neste trabalho para a característica de número de folha apresentou superior ao citado (Tabela 1).

$\mathrm{Na}$ Tabela 2 pode-se observar que no inverno cada uma das cultivares se destacaram para característica produção comercial em relação ao verão, diferindo estatisticamente pelo teste Tukey a 5\%, demonstrando desta maneira um grande desempenho da cultura em clima mais ameno. Já na comparação entre as cultivares em cada época de cultivo pode-se observar que no período de inverno houve diferença significativa entre as cultivares, dando destaque para as cultivares Verônica e Cinderela que obtiveram a mesma significância porém se destacando das demais, já no período de verão não obteve diferença significativa entre as cultivares.

Tabela 2 - Resultado da comparação entre médias de cada cultivar de alface em relação à produção comercial $\left(\mathrm{g}_{\text {planta }}{ }^{-1}\right)$, cultivados sob diferentes épocas (inverno e verão), Cáceres-MT, 2011

\begin{tabular}{llr}
\hline \multicolumn{1}{c}{ Cultivares } & \multicolumn{1}{c}{ Inverno } & \multicolumn{1}{c}{ Verão } \\
\hline Verônica & $301,1429 \mathrm{~A} \mathrm{a}$ & $123,8536 \mathrm{~B} \mathrm{a}$ \\
Vera & $236,5357 \mathrm{~A} \mathrm{ab}$ & $85,0429 \mathrm{~B} \mathrm{a}$ \\
Cinderela & $272,5714 \mathrm{~A} \mathrm{a}$ & $107,7821 \mathrm{~B} \mathrm{a}$ \\
Isabela & $193,5357 \mathrm{~A} \mathrm{~b}$ & $94,0964 \mathrm{~B} \mathrm{a}$ \\
Veneranda & $237,7857 \mathrm{~A} \mathrm{ab}$ & $97,5071 \mathrm{~B} \mathrm{a}$ \\
\hline
\end{tabular}

Médias seguidas pelas mesmas letras maiúsculas na horizontal e minúsculas na vertical não diferem estatisticamente entre si pelo teste Tukey a $5 \%$

No trabalho realizado por Yuri et al. (2002) a produção comercial de alface tipo americana no inverno não mostrou diferença significativa entre as cultivares Cassino, Legacy, Lucy Brown, Lorca, Lady e Raider. Para o verão as cultivares Raider, Cassino, Lady, Legacy e Lorca apresentaram os maiores rendimentos, demonstrando a diferença que ocorre entre períodos diferentes de produção. 
Para a característica número de folhas pode-se observar na Tabela 3, que ao comparar cada cultivar em relação a época de cultivo, no período de inverno as plantas tiveram índice foliar mais alto para todas as cultivares. Comparando o desempenho das cinco cultivares dentro de cada época as cultivares Cinderela, Verônica e Isabela obtiveram diferença significativa em relação às outras cultivares em ambas as épocas de produção. Com a análise dos dados observouse a diferença que há na produção entre as épocas de cultivo, onde o período de inverno se destacou com os maiores valores, porém a comparação da produção nos dois períodos analisando a estabilidade das cultivares levará aos produtores um genótipo mais estável proporcionando uma melhor produção, consequentemente uma maior lucratividade.

Tabela 3 - Resultado da comparação entre médias de cada cultivar de alface em relação ao número de folhas, cultivados sob diferentes épocas de produção (inverno e verão), submetido ao teste Tukey a 5\%. Cáceres-MT, 2011

\begin{tabular}{lll}
\hline \multicolumn{1}{c}{ Cultivares } & \multicolumn{1}{c}{ Inverno } & \multicolumn{1}{c}{ Verão } \\
\hline Verônica & $20,60 \mathrm{~A} \mathrm{ab}$ & $13,86 \mathrm{~B} \mathrm{ab}$ \\
Vera & $18,12 \mathrm{~A} \mathrm{~b}$ & $12,77 \mathrm{~B} \mathrm{~b}$ \\
Cinderela & $22,69 \mathrm{~A} \mathrm{a}$ & $17,01 \mathrm{~B} \mathrm{a}$ \\
Isabela & $20,13 \mathrm{~A} \mathrm{ab}$ & $15,02 \mathrm{~B} \mathrm{ab}$ \\
Veneranda & $18,16 \mathrm{~A} \mathrm{~b}$ & $13,15 \mathrm{~B} \mathrm{~b}$ \\
\hline
\end{tabular}

Médias seguidas pelas mesmas letras maiúsculas na horizontal e minúsculas na vertical não diferem estatisticamente entre si

A adaptação de uma cultivar em uma ampla extensão de épocas de plantio é considerada de interesse para o melhorista (BORÉM, 1998). De acordo com esta afirmação pode-se dizer que as médias obtidas entre as variáveis avaliadas apresentou diferença e isto se deve à interação dos diferentes genótipos com os ambientes e épocas de cultivo, relacionado com o potencial genético de cada cultivar. Deve-se considerar que as temperaturas em Cáceres MT são extremamente elevadas, prejudicando o cultivo da alface (SANTOS et al., 2009). Segundo Branco (2001) comparando-se as melhores épocas do ano para o plantio, verifica-se que as plantas de alface acumulam menos matéria seca na parte aérea nas épocas mais quentes, principalmente no plantio de verão devido ao estresse térmico por altas temperaturas.

A Figura 1 demonstra a existência da diferença dos coeficientes de regressão dos genótipos em relação à produção comercial, e a adaptabilidade e estabilidade existente.

Os valores encontrados para produção comercial foram semelhantes aos de produção total, onde a cultivar Verônica foi a que se destacou com $100 \%$ estabilidade fenotípica e com um baixo índice de interação genótipo $\mathrm{x}$ ambiente. A cultivar Isabela possui grande interação genótipo $\mathrm{x}$ ambiente, já a cultivar Cinderela novamente obteve um bom índice de estabilidade chegando a $85 \%$ (Figura 1). Segundo Sanchez (2007) em seu trabalho sobre alface crespa produzidas em hidroponia em dois ambientes na cidade de Ribeirão Preto-SP observou que as cultivares que mais se destacaram em massa fresca da parte aérea, indicando uma produção dentro dos padrões comerciais para a espécie, foram as cultivares Crespona gigante, com 179,17 $\mathrm{g}_{\text {planta }}{ }^{-1}$ e Verônica com 118,72 $\mathrm{g}_{\text {planta }}{ }^{-1}$, demonstrando um grande potencial produtivo para cultivar Verônica.

Figura 1 - Índice de estabilidade dos genótipos para produção comercial das cultivares em diferentes épocas de cultivo, UNEMAT, 2011

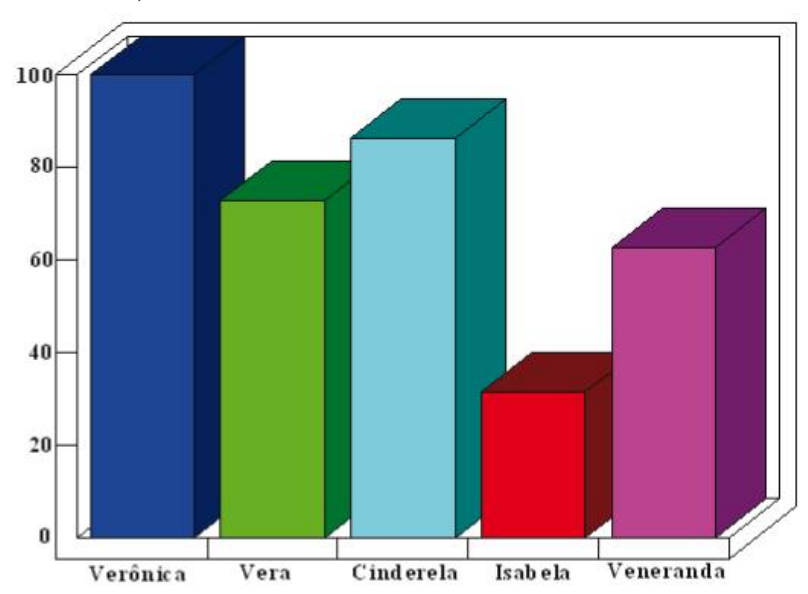

Gualberto, Oliveira e Guimarães (2009) também verificaram em seus experimentos de adaptabilidade e estabilidade de alface em cultivo hidropônico que a cultivar Verônica destacou-se entre as demais, apresentando uma das melhores massas da matéria fresca da parte aérea, classificando-a ainda como a de maior adaptabilidade geral nos ambientes de cultivo. Já no experimento realizado por Schimidt et al. (2000) a cultivar Verônica apresentou os piores resultados com uma massa fresca de $99,41 \mathrm{~g}$ planta $^{-1}$ e seca $4,41 \mathrm{~g}_{\text {planta }}{ }^{-1}$.

Segundo Rodrigues et al. (2008) além de ser tradicionalmente plantado pelos horticultores de Manaus 
AM, a cultivar Verônica revelou maior rusticidade e adaptação a períodos de intensa precipitação pluviométrica. Isso demonstra a grande capacidade de adaptação a uma situação adversa de produção demonstrando a baixa interação genótipo $\mathrm{x}$ época de cultivo.

Na Figura 2 pode-se verificar a diferença que cada cultivar sofreu na característica número de folhas em relação às variações ambientais quando produzidas em diferentes épocas de cultivo, umas obtendo baixa e outras alta interação G x E.

Figura 2 - Índice de estabilidade dos genótipos para numero de folhas das cultivares em diferentes épocas de cultivo, UNEMAT, 2011

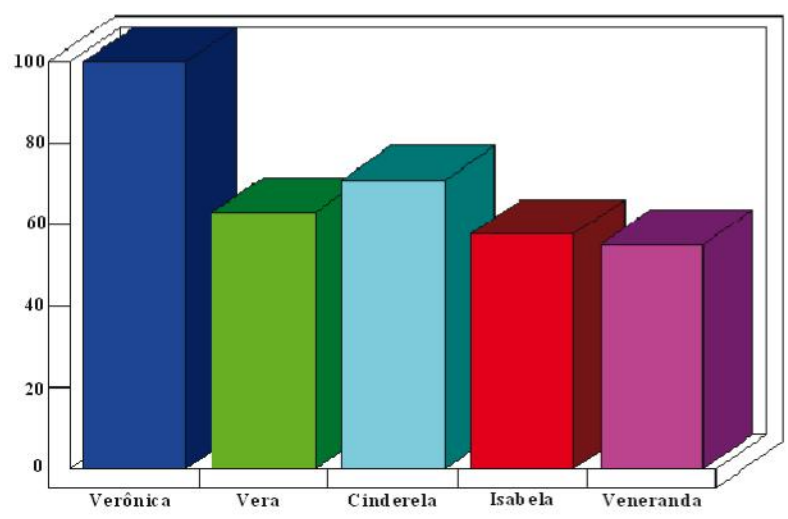

A cultivar Verônica se destacou com maior número de folhas que as demais e se manteve com menor índice de interação (100\%) demonstrando o grande destaque da cultivar na sua produção em diferentes épocas de cultivo. Gualberto, Oliveira e Guimarães. (2009) relatam em seu trabalho de adaptabilidade e estabilidade de alface em cultivo hidropônico que o número de folhas por planta, as cultivar Deyse, Sabrina e Verônica sobressaíram-se por mostrarem ampla adaptabilidade a todos os ambientes e número de folhas por planta estatisticamente iguais à cultivar de maior valor a qual seria a cultivar Elba.

Os demais genótipos não tiveram diferença significativa em relação ao número de folhas, obtendo uma média de 60 a $70 \%$ de estabilidade fenotípica. A variação de desempenho de diferentes genótipos de alface tem sido observada nas diversas regiões do Brasil, onde cada cultivar expressa de forma distinta seu potencial genético quando submetidas em diferentes condições ambientais.

Segundo Sediyama et al. (2009) a característica numero de folha é de grande interesse para uma boa produção, e temperaturas muito elevadas acelera a fase vegetativa da planta fazendo com que comece a ocorrer o pendoamento precoce, à medida que ocorre a emissão do pendão floral há uma redução no número de folhas. Por isso se faz necessário obter cultivares com boa adaptabilidade e estabilidade sendo imprescindível para uma boa produção.

Foi observado neste trabalho que a diferença entre as épocas de produção e os resultados obtidos em cada ambiente, no inverno de 2009 obteve média geral das cultivares de 19,94 folhas, demonstrando o índice foliar mais elevado, e no verão de 2008 obteve média de 14,36 folhas. Resultados favoráveis ao período de inverno foram constatados no trabalho de Feltrim et al. (2009) onde o número médio de folhas das cultivares Vera e Verônica foi de 29,5 em solo e cultivo hidropônico em ambas as épocas de cultivo.

\section{CONCLUSÃO}

Com o uso desta tecnologia de cultivo pode-se concluir que há diferença no desempenho das cultivares em relação às épocas de cultivo, possibilitando desta maneira uma excelente produção durante o ano na região de Cáceres - MT. Os parâmetros do coeficiente de determinação e índice de variação da variável número de folhas são próximos da unidade apresentando uma maior estabilidade genética. Em relação à adaptabilidade e estabilidade fenotípica a cultivar Verônica foi a que se manteve mais estável nos períodos de produção, respondendo melhor às épocas de cultivo sendo ela a mais indicada para os produtores da região. A cultivar Cinderela, em relação às outras cultivares, manteve uma boa produção sendo a segunda opção para o cultivo.

\section{AGRADECIMENTOS}

À Fundação de Amparo à Pesquisa do Estado de Mato Grosso pelo financiamento do projeto, processo $N^{\circ} 822 / 2006$. As empresas Sakata Seed Suldamerica e Feltrin Sementes pela indicação das cultivares e doação das sementes.

\section{REFERÊNCIAS}

BEZERRA NETO, F. et al. Sombreamento para produção de mudas de alface em alta temperatura e ampla luminosidade. Horticultura Brasileira, v. 23, n. 2 p. 133-137. 2005.

BORÉM, A. Melhoramento de Plantas. Viçosa: UFV, 2008. $453 \mathrm{p}$. 
BRANCO, R. B. F. Avaliação de cultivares e épocas de cultivo de alface nas condições de solo e hidroponia, em ambiente protegido. 2001. 80 f. Dissertação (Mestrado em Agronomia-Produção vegetal) - Faculdade de Ciências Agrárias e Veterinárias, Universidade Estadual Paulista, Jaboticabal, 2001.

CRUZ, C. D. Programa Genes: estatística experimental e matrizes. Viçosa: UFV, 2006. p. 285.

CRUZ, C. D. Princípios de genética quantitativa. Viçosa: UFV, 2005. 394 p.

DIAMANTE, S. M. et al. Produção e resistência ao pendoamento de alfaces tipo lisa cultivadas sob diferentes ambientes. Revista Ciência Agronômica, v. 44, n. 1, p. 133-140, 2013.

ECHER, M. M. et al. Comportamento de cultivares de alface em função do espaçamento. Revista de Agricultura, v. 76, p. 267-275, 2001.

FELTRIM, A. L. et al. Produção de alface-crespa em solo e em hidroponia, no inverno e verão, em Jaboticabal - SP. Científica, v. 37 , n. 1, p. 9-15. 2009.

FILGUEIRA, F. A. R. Novo manual de Olericultura: agrotecnologia moderna na produção e comercialização de hortaliças. Viçosa: editora Ceres, 2003412 p.

GUALBERTO, R.; OLIVEIRA, P. S. R.; GUIMARÃES, A. M. Adaptabilidade e estabilidade fenotípica de cultivares de alface do grupo crespa em cultivo hidropônico. Horticultura Brasileira, v. 27, n. 1. p.007-011. 2009.

NEVES, S. A. S. M. et al. Caracterização das condições climáticas de Cáceres/MT/Brasil, no período de 1971 a 2009: subsídio às atividades agropecuárias e turísticas municipais. Boletim Goiano de Geografia, v. 31, n. 2, p. 55-68, 2011.

NEVES, S. M. A. S. Condição climática de Cáceres/MT. In: SIMPÓSIO BRASILEIRO DE CLIMATOLOGIA GEOGRÁFICA: OS CLIMAS E A PRODUÇÃO DO ESPAÇO NO BRASIL, 7., 2006, Rondonópolis. Anais... Rondonópolis: UFMT, 2006.

OLIVEIRA, A. C. B. et al. Divergência genética e descarte de variáveis em alface cultivada sob sistema hidropônico. Acta Scientiarum Agronomy, v. 26, n. 2, p. 211-217, 2003.

QUEIROGA, R. C. F. et al. Produção de alface em função de cultivares e tipos de tela de sombreamento nas condições de Mossoró. Horticultura Brasileira, v. 19, n. 3, p. 192-196, 2001.

RADIN, B. et al. Crescimento de cultivares de alface em estufa e a campo. Horticultura Brasileira, v. 22, n. 2, p. 178-181, 2004.

RODRIGUES, I. N. et al. Desempenho de cultivares de alface na região de Manaus. Horticultura Brasileira, v. 26, n. 4, p. 524-527, 2008.

ROSSE, L. N.; VENCOVSKY, R. Modelo de regressão não-linear aplicado ao estudo da estabilidade fenotípica de genótipos de feijão no Estado do Paraná. Bragantia, v. 59, n. 1, p. 99-107, 2000.

ROSSMANN, H. Estimativas de parâmetros genéticos e fenotípicos de uma população de soja avaliada em quatro anos. 2001. $80 \mathrm{f}$. Tese (Doutorado em Agronomia) - Escola Superior de Agricultura "Luiz de Queiroz", Universidade de São Paulo, Piracicaba, 2001.

SALATIEL, L. T. et al. Avaliação de cultivares de alface, cultivadas em casa de vegetação, em três épocas de plantio. Horticultura Brasileira, v. 18, p. 703-704, 2001.

SANCHEZ, S. V. Avaliação de cultivares de alface crespa produzidas em hidroponia tipo NFT em dois ambientes protegidos em Ribeirão Preto (SP). 2007. 63 f. Dissertação (Mestrado em Agronomia - Produção Vegetal) - Universidade Estadual Paulista, Faculdade de Ciências Agrárias e Veterinárias, Jaboticabal., 2007.

SANTOS L. L; SEABRA JUNIOR S; NUNES, M. C. M. Luminosidade, temperatura do ar e do solo em ambientes de cultivo protegido. Revista de Ciências Agro-Ambientais, v. 8, n. 1, p. 83- 93. 2010.

SANTOS, C. L. et al. Desempenho de cultivares de alface tipo crespa sob altas temperaturas em Cáceres-MT. Agrarian, v. 2 , n. 3 , p. $87-98,2009$.

SCHIMIDT, D. et al. Eficiência de soluções hidropônicas em cultivo de alface. In: CONGRESSO BRASILEIRO DE OLERICULTURA, 40., 2000, São Pedro. Resumos... São Pedro: SOB, 2000. p. 269-271.

SEABRA JÚNIOR, S. et al. Cultivo de alface em Cáceres/MT: perspectivas e desafios. Revista Conexão UEPG, v. 08, n. 1, p. 130-137, 2012.

SEDIYAMA, M. A. N. et al. Desempenho de cultivares de alface para cultivo hidropônico no verão e no inverno. Científica, v. 37, n. 2, p. 98-106. 2009.

SILVA, C. E.; LEAL, R. N.; MALUF, R. W. Avaliação de cultivares de alface sob altas temperaturas em cultivo protegido em três épocas de plantio na região NorteFluminense. Ciência e Agrotecnologia., v. 23, n. 3, p. 491499, 1999.

SOUZA, M. C. M. et al. Variabilidade genética para características agronômicas em progênies de alface tolerante ao calor. Horticultura Brasileira, v. 26, n. 3, p. 354-358, 2008.

TRANI, P. E. et al. Desempenho de cultivares de Alface sob cultivo protegido. Centro de horticultura. Bragantia, v. 65, n. 3, p. 441-445, 1997.

YURI, J. E. et al. Comportamento de cultivares de alface tipo americana em Boa Esperança. Horticultura Brasileira, v. 20, n. 2, p. 229-232, 2002. 